\title{
Administration of encapsulated L-tryptophan improves duodenal starch digestion and increases gastrointestinal hormones secretions in beef cattle
}

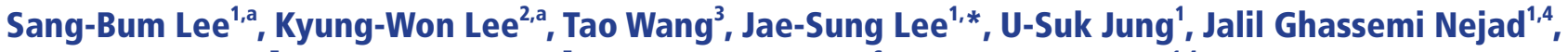 \\ Young-Kyoon $\mathrm{Oh}^{5}$, Youl-Chang Baek ${ }^{5}$, Kyoung Hoon $\mathrm{Kim}^{6}$, and Hong-Gu Lee ${ }^{1,4, *}$
}

\author{
* Corresponding Authors: \\ Jae-Sung Lee \\ Tel: +82-2-4500410, Fax: +82-2-4533669 \\ E-mail: jslee78@konkuk.ac.kr \\ Hong-Gu Lee \\ Tel: +82-2-2450-0523, Fax: +82-2-4533669 \\ E-mail: hglee66@konkuk.ac.kr
}

1 Department of Animal Science and Technology, Sanghuh College of Life Sciences, Konkuk University, Seoul 05029, Korea

2 Life Science Technology, Inc., Seoul 06134, Korea

${ }^{3}$ Department of Animal Nutrition and Feed Science, College of Animal Science and Technology, Jilin

Agricultural University, Jilin 130118, China

${ }^{4}$ Team of an Educational Program for Specialists in Global Animal Science, Brain Korea 21 Plus Project, Sanghuh College of Life Sciences, Konkuk University, Seoul 05029, Korea

${ }^{5}$ Department of Nutrition and Physiology, National Institute of Animal Science, RDA, JeonJu 55365 , Korea

${ }^{6}$ Graduate School of International Agricultural Technology, Pyeongchang Campus, Seoul National University, Pyeongchang 25354, Korea

a SB Lee and KW Lee equally contributed to this work.

ORCID

Sang-Bum Lee

https://orcid.org/0000-0001-5761-8483 Kyung-Won Lee

https://orcid.org/0000-0001-8019-1860 Tao Wang

https://orcid.org/0000-0002-1876-0097 Jae-Sung Lee

https://orcid.org/0000-0001-8940-9862

U-Suk Jung

https://orcid.org/0000-0003-4125-6179 Jalil Ghassemi Nejad

https://orcid.org/0000-0001-6578-8829 Young-Kyoon Oh

https://orcid.org/0000-0002-5817-1748

Youl-Chang Baek

https://orcid.org/0000-0003-4454-5339

Kyoung Hoon Kim

https://orcid.org/0000-0002-7288-7443

Hong-Gu Lee

https://orcid.org/0000-0002-0679-5663

Submitted Jun 17, 2019; Revised Aug 23, 2019; Accepted Oct 30, 2019
Objective: This study investigated the effects of oral administration of rumen-protected L-tryptophan (RPL-T) on duodenal starch digestion and gastrointestinal hormones (GIH) secretions using Hanwoo beef steers as the animal models.

Methods: Four steers $(423 \pm 24 \mathrm{~kg}$ ) fitted with ruminal and duodenal cannulas were employed in a crossover design replicated twice. Treatments were control (basal diet) and RPL-T (basal diet+191.1 mg/kg body weight [BW]) group. Blood and duodenal samples were collected to measure serum GIH levels and pancreatic $\alpha$-amylase activity at day $0,1,3$, and $5(-30,30$, 90,150 , and $210 \mathrm{~min}$ ) of the study. Samples from each segment of the gastrointestinal tract were collected via ruminal and duodenal cannulas and were used to determine soluble protein and the starch digestion rate at days $6(-30,180,360$, and $540 \mathrm{~min})$ and $8(-30,90,270$, and $450 \mathrm{~min}$ ) of the experiment.

Results: No significant difference in ruminal $\mathrm{pH}, \mathrm{NH}_{3}-\mathrm{N}$, and total volatile fatty acid including the levels of acetate, propionate, butyrate, isobutyrate, valerate, isovalerate, and the acetateto-propionate ratio was observed between groups $(\mathrm{p}>0.05)$. Crude protein uptake was higher and feces starch content was lower in RPL-T group than the control group $(p<0.05)$. The D-glucose contents of feces in RPL-T group decreased at day 5 compared to those in the control group $(p<0.05)$, however, no change was found at day 0,1 , or 3 compared to the control group ( $\mathrm{p}>0.05)$. Serum cholecystokinin $(\mathrm{CCK})$, melatonin, duodenal pancreatic a-amylase activity, and starch digestion were significantly higher in RPL-T group than the control group $(\mathrm{p}<0.05)$.

Conclusion: Taken together, oral administration of RPL-T at the rate of $191.1 \mathrm{mg} / \mathrm{kg}$ BW consistently increased CCK concentration, pancreatic $\alpha$-amylase activity in duodenal fluids, and starch digestion rate in the small intestine and thus found to be beneficial.

Keywords: a-Amylase; Cholecystokinin; L-tryptophan; Monogastric; Polygastric Model; Protein

\section{INTRODUCTION}

L-tryptophan (L-T) is involved in the production of serotonin [1,2], melatonin (MEL) [3,4], and a precursor of nicotinic acid [5]. Precedent studies in monogastric animals (e.g., humans, pigs, dogs, rats, mice, and chickens) elucidated the pivotal biological role of tryptophan (TRP) in association with different metabolic processes [6] including increased MEL in rainbow trout [7] that is also associated with stressed animals [3]. In humans, infusion of L-T has been shown to increase prolactin and growth hormone secretions [8]. Moreover, in mammalian, the protective roles of MEL and TRP on increase of gastric mucosa and stimulation of cholecystokinin (CCK) and pancreatic exocrine function via enteropancreatic reflex mech- 
anism has been reported [4]. However, little is known about the possible similar effects in ruminants as polygastric animal models.

Given that undigested starch in the rumen of polygastric animals passes into the lower digestive organs, a small amount of $\alpha$-amylase is secreted into the small intestine with extremely low activity where only $35 \%$ to $60 \%$ of starch is digested [9]. The remaining $35 \%$ to $50 \%$ of the starch is excreted in undigested form through feces [10]. In other words, starch digestion in the small intestines of ruminants can be modulated by the environment inside of the small intestine. It is while a similar phenomenon was previously reported in broiler chicks [11] and weaned piglets [12]. Therefore, any attempts to improve a-amylase activity in duodenal fluids could help starch digestion, which is also targeted in the present study.

The most recent study in our laboratory [13] demonstrated that the intravenous administration of L-T $(57.8 \mathrm{mg} \mathrm{L}-\mathrm{T} / \mathrm{kg}$ body weight $[\mathrm{BW}]$ ) increased the secretion of MEL in growing beef steers. From these results, and due to the rate of absorption and disappearance of L-T $(\sim 72 \%)$ in gastro-intestinal (GI) tract, we hypothesized that using $200 \mathrm{mg} / \mathrm{kg}$ BW of RPLT may lead to similar results if provided orally. Additionally, there are GI related hormones that stimulate the rate of feed digestion including CCK, MEL, and secretin that are associated with L-T. As demonstrated by Leja-Szpak et al [14] the effects of the administration of L-T on MEL synthesis in mice resulted in higher MEL levels. Both L-T and MEL are closely related to CCK, an endocrine hormone that can eventually increase the synthesis of pancreatic $\alpha$-amylase. In studies on ruminants, administration of L-T to the jugular vein of dairy cows reported increasing the secretion of serotonin [14]. Additionally, evidences showed that an increase in MEL and ghrelin by L-T stimulated the secretion of CCK and $\alpha$-amylase in monogastric animals $[14,15]$. However, it is yet to prove the role of L-T in association with starch degradation in polygastric animals. Therefore, this study was undertaken to determine if similar endocrine and digestive effects would be elicited by oral administration of RPL-T empirically using beef cattle as experimental animal models. We elected not to observe changes in ruminal characteristics due to using encapsulated (rumen-protected) L-T; and thus to test this hypothesis and in addition to measure the main parameters, we analysed the rumen fluid characteristics in this study to see if L-T in the encapsulated form can successfully bypass through the rumen without degradation.

\section{MATERIALS AND METHODS}

\section{Animals and treatment preparation}

All experimental procedures were in accordance with the "Guidelines for Care and Use of Experimental Animals" of Pusan National University (approval no.: PNU-2010-000152).
Four Korean native steers (ave. BW $=423 \pm 24 \mathrm{~kg}$ ) and cannulated in their rumen and duodenum were employed. Animals were kept in the individual cattle sheds with concrete floors and fence of $3 \times 3.2 \mathrm{~m}$ under illumination and heat control (16 $\mathrm{h}$ of lights-on, $8 \mathrm{~h}$ of lights-out at $23^{\circ} \mathrm{C}$ ). They were provided free access to water and salt blocks. Basic feed was composed of rice straw (31.3\%) and growing-fattening feed (68.7\%). Diet were formulated by Grobig DC (vitamin A, 2,650,000 IU; vita$\min \mathrm{D}_{3}, 530,000 \mathrm{IU}$; vitamin E, 1,050 IU; nicotinic acid, 10,000 mg; Fe, 13,200 mg; Mn, 4,400 mg; Zn, 4,400 mg; copper, 2,200 mg; iodine, $440 \mathrm{mg}$; cobalt, $440 \mathrm{mg}$ ) and were composed of dry matter $(\mathrm{DM})=93.5$, starch $=48.8$, curde protein $(\mathrm{CP})=$ 14.1 (Supplementary Table S1-1) based on recommendations by National Institute of Animal Science [16]. The BW was measured prior to each period. Animals were fed twice daily at 0800 and $1700 \mathrm{~h}$ for 11 days before treatment. Metabolizable energy uptake was controlled to 1.2-times more than that required for Korean native steers [16] in order to ensure that each animal receiving enough energy uptake. Chrome oxide $\left(\mathrm{Cr}_{2} \mathrm{O}_{3}\right)$ was added to the growing-fattening feed at $0.2 \%$ as a marker to measure the contents of digesta. The RPL-T ( $42 \%$ L-T, Beijing Feeding Feed Science Technology CO., Beijing, China) was used in this study. RPL-T is a mixture of granules (42\% L-T, 37.7\% fat, and 20.3\% carbohydrates) wrapped by resin made of complex organic acids and their derivatives. The amount of RPL-T (191.1 mg/kg BW) used in this study was calculated based on the dose used in the most recent study [13] in our laboratory to define the effective dosages (57.8 $\mathrm{mg} / \mathrm{kg} \mathrm{BW}$ ) and the average absorption rate (72\%) of L-T in the small intestine of ruminants [17]. Steers were randomly assigned to each group in a crossover design, and the experiment was repeated twice. Animals were allowed to adapt to the basic feed for 11 days before treatment. After the adaptation period, two different diets were used: i) basal diet $(31.3 \%$ of rice straw $+68.7 \%$ of concentrate) + RPL-T (encompassing $42 \% \mathrm{~L}-\mathrm{T}$ ), giving $191.1 \mathrm{mg} / \mathrm{kg} \mathrm{BW}$ (treatment group); ii) basal diet $+58 \%$ of diluting agent, giving $191.1 \mathrm{mg} / \mathrm{kg} \mathrm{BW}$ (control group). Steers were fed for 1 to 8 days per treatment period with 4 days of rest between treatment periods for a total of 20 days with two feeding treatment periods. The amount of diet for the treatment was determined based on individual BW measured 1 day prior to treatment administration.

\section{Sampling}

Diet sampling: Daily feed uptake was recorded in this experiment. Samples of the diet were collected for 6 to 8 days of beginning, mid and end of experiment. All samples were ground to $1 \mathrm{~mm}$ in size using a Wiley mill (Thomas Scientific, Model 4, Swedesboro, NJ, USA) and dried for the following proximate analyses.

Serum sampling: Blood samples were harvested from the jugular vein in evacuated tubes with no additives to obtain 
serum. Times of the sample collections were at $-30 \mathrm{~min}(0830$ h), $30 \mathrm{~min}(0930 \mathrm{~h}), 90 \mathrm{~min}(1030 \mathrm{~h}), 150 \mathrm{~min}(1130 \mathrm{~h})$, and $210 \mathrm{~min}(1230 \mathrm{~h})$ on day 0 (before treatment), day 1 , day 3 , and day 5. After blood collection, serum was obtained by centrifugation $\left(1,200 \times \mathrm{g}\right.$ for $\left.20 \mathrm{~min}, 4^{\circ} \mathrm{C}\right)$ and then placed into storage tubes and stored at $-20^{\circ} \mathrm{C}$ until further analysis.

Duodenum fluids sampling: Duodenum fluids $(250 \mathrm{~mL})$ were sampled through a duodenum cannula to analyze the rate of starch digestion in each section of the intestine at -30 $\min (0830 \mathrm{~h}), 180 \mathrm{~min}(1200 \mathrm{~h}), 360 \mathrm{~min}(1500 \mathrm{~h})$, and 540 $\min (1800 \mathrm{~h})$ on day 6 , and at $-30 \mathrm{~min}(0830 \mathrm{~h}), 90 \mathrm{~min}(1030$ h), $270 \mathrm{~min}(1330 \mathrm{~h})$, and $450 \mathrm{~min}(1630 \mathrm{~h})$ on day 8 . These fluids were lyophilized (Programmable Freeze dryer, Ilshin lab Co., Ltd., Seoul, Korea) and ground to $1 \mathrm{~mm}$ in size using a Disc Mill (Model BM-D 100, McCoy Corporation, San Marcos, TX, USA). Samples were mixed together for the analysis of DM, CP, ash, and starch [18]. A $50 \mathrm{~mL}$ sample of duodenal fluid was sampled via the cannula for the analysis of $\alpha$-amylase activity at $-30 \mathrm{~min}(0830 \mathrm{~h}), 30 \mathrm{~min}(0930 \mathrm{~h}), 90 \mathrm{~min}$ (1030 h), $150 \mathrm{~min}(1130 \mathrm{~h})$, and $210 \mathrm{~min}(1230 \mathrm{~h})$ on days $0,1,3$, and 5 of each period. Samples were frozen at $-80^{\circ} \mathrm{C}$ before analysis.

Rumen fluids sampling: A $300 \mathrm{~mL}$ ruminal fluid was collected for the analysis of starch digestion at each section of the intestine at $-30 \mathrm{~min}(0830 \mathrm{~h}), 60 \mathrm{~min}(1000 \mathrm{~h}), 180 \mathrm{~min}$ $(1200 \mathrm{~h})$, and $300 \mathrm{~min}(1400 \mathrm{~h})$ for each treatment on day 6 and day 8 . The fluids were filtered with a four-layer gauze immediately after sampling. The $\mathrm{pH}$ was measured using Seveneasy $\mathrm{pH}$ meters (Mettler-Toledo AG 8603, Schweraenbach, Switzerland) followed by a preconditioning process to analyze ammonia and volatile fatty acids (VFA). Samples were frozen at $-80^{\circ} \mathrm{C}$ before analysis.

Feces sampling: Approximately $300 \mathrm{~g}$ of feces were obtained from the rectum using a recto-vaginal technique at the same collection time that duodenal fluids were taken, and stored at $-80^{\circ} \mathrm{C}$. Samples were dried and ground to $1 \mathrm{~mm}$ in size for the analysis of the DM, CP, ash, and starch using AOAC [18]. Chromium oxide $\left(\mathrm{Cr}_{2} \mathrm{O}_{3}\right)$ was used to track digestion in a different section of GI tract.

\section{Analyses}

Ruminal characteristics ( $\mathrm{NH}_{3}-\mathrm{N}$ and VFA): The concentration of ammonia was analyzed using the method by Chaney and Marbach [19]. Samples were preconditioned by adding $10 \mu \mathrm{L}$ of $\mathrm{HgCl}_{2}$ to $1 \mathrm{~mL}$ of ruminal fluids in a $1.5 \mathrm{~mL}$ micro tube. Samples were mixed to deactivate microorganisms in the rumen. Samples were stored in a deep freezer $\left(-80^{\circ} \mathrm{C}\right)$ until analysis. During the assays, samples were thawed at room temperature and centrifuged $(13,500 \times \mathrm{g}, 5 \mathrm{~min})$ to obtain 20 $\mu \mathrm{L}$ of supernatant. Supernatant, distilled water, and ammonia standard solutions $\left(2.5,5,10,20\right.$, and $40 \mathrm{mg} \mathrm{NH}_{3}-\mathrm{N} / 100$ $\mathrm{mL}$ ) were added to three sets of $20 \mathrm{~mL}$ tubes. One milliliter of phenol color reagent (distilled water $1 \mathrm{~L}$; phenol $\left[\mathrm{C}_{6} \mathrm{H}_{5} \mathrm{OH}\right]$ 50 g; sodium nitroferricyanide $\left[\mathrm{Na}_{2}\left(\mathrm{Fe}[\mathrm{CN}]_{5} \mathrm{NO}\right) \cdot 2 \mathrm{H}_{2} \mathrm{O}\right]$; alkali-hypochlorite reagent [distilled water $1 \mathrm{~L}$, sodium hydroxide (NaOH) $25 \mathrm{~g}$ ]; and sodium hydrochloride [4\% to $6 \%$ $\mathrm{NaOCl}] 16.8 \mathrm{~mL}$ ) was added to each tube, mixed, sealed with a butyl rubber stopper, and incubated at $37^{\circ} \mathrm{C}$ in a constanttemperature water bath for $15 \mathrm{~min}$. After incubation, $8 \mathrm{~mL}$ of distilled water was added to measure the absorbance (optical density) at $630 \mathrm{~nm}$ using a spectrophotometer (Bio-Rad, US/benchmark plus, Tokyo, Japan). Ammonia concentrations in the samples were determined using a standard calibration curve. The VFAs in the rumen was measured using the method described by Erwin et al [20]. Samples were preconditioned by adding $10 \mu \mathrm{L}$ of $\mathrm{HgCl}_{2}$ to $1 \mathrm{~mL}$ of rumen fluids in a $1.5 \mathrm{~mL}$ micro tube. Samples were mixed to deactivate microorganisms in rumen. After that, $200 \mu \mathrm{L}$ of $\mathrm{H}_{3} \mathrm{PO}_{4}$ was added to remove proteins from microorganisms, and $40 \mu \mathrm{L}$ of pivalic acid was added as an internal standard for gas chromatography (GC). The solution was mixed and stored in a deep freezer $\left(-80^{\circ} \mathrm{C}\right)$ until analysis. All analyses were repeated at least three times. During assays, samples were thawed at room temperature and centrifuged $(13,500 \times \mathrm{g}, 5 \mathrm{~min})$ to obtain the supernatant for GC analysis (VARIAN model CP-3800, Walnut Creek, CA, USA). The VFAs standard solution was made by mixing 100 $\mathrm{mL}$ distilled water, with acetate $350 \mu \mathrm{L}$, propionate $150 \mu \mathrm{L}$, isobutyrate $50 \mu \mathrm{L}$, butyrate $100 \mu \mathrm{L}$, isovalerate $50 \mu \mathrm{L}$, valerate $50 \mu \mathrm{L}$, and $5 \mathrm{~mL}$ of standard solution $(200 \mu \mathrm{L}$ of pivalic acid and $1.05 \mathrm{~mL}$ of distilled water). One milliliter of this solution was used as a VFA standard. The contents of VFA in the sample were determined using a standard calibration curve.

Immunoassay for establishing and analyzing GIH (ghrelin, secretin, and CCK-8) and MEL in bovine serum: Serum concentrations of ghrelin, secretin, and CCK- 8 were measured by enzyme immunoassay using secondary antibodies for ghrelin (EK-031-30), secretin (EK-067-05), and CCK-8 (EK-069-04) (Phoenix Pharmaceuticals, Burlingame, CA, USA) with a human MEL ELISA Kit (RE54021) (IBL, Hamberg, Germany). Serum was prepared for analyses and to test the cross-reactivity of standards in the kit using the method described by Lee et al [6].

Determination of $\alpha$-amylase activity in duodenal fluid of the exocrine pancreas: $\alpha$-Amylase activity in duodenal fluid secreted from the exocrine glands of the pancreas was determined using the EnzyChrom a-amylase Assay Kit (ECAM100, BioAssay Systems, Hayward, CA, USA).

Analysis of starch digestibility in gastrointestinal fluids: To analyze starch digestibility in each section of the intestine, the Anthrone Method [21] using D-glucose standard solution and the method described by McCready et al [22] were used. In brief, frozen intestinal fluid was thawed at room temperature and ground to less than $0.5 \mathrm{~mm}$ in an icebox using a homogenizer. The homogenate was filtered through a 2-layer 
gauze (sieve less than $0.5 \mathrm{~mm}$ ). Five-milliliters of anthrone solution $(0.1 \mathrm{~g}$ of anthrone dissolved in $100 \mathrm{~mL}$ of the solution made by diluting $760 \mathrm{~mL}$ of sulfuric acid to distilled water to make $1 \mathrm{~L}$ ) was added to $1 \mathrm{~mL}$ of supernatant to assess color change. After centrifugation, supernatants were removed and the precipitates were dried at $40^{\circ} \mathrm{C}$ to $50^{\circ} \mathrm{C}$ for $60 \mathrm{~min}$ to completely remove ethanol. Care was taken to keep the temperature below $60^{\circ} \mathrm{C}$ in order to prevent the degradation of glucose and protein. After drying, $5 \mathrm{~mL}$ of distilled water was added and mixed well followed by the addition of $6.5 \mathrm{~mL}$ of $52 \%$ perchloric acid reagent. Next, supernatants were filtered and moved to a $100 \mathrm{~mL}$ volumetric flask. The waste residue of the sample was filtered with distilled water to a final volume of $100 \mathrm{~mL}$, which was the last step of preconditioning. One milliliter of the sample solution and different concentrations of standard solutions $(25,50,100,150$, and $200 \mu \mathrm{g} / \mathrm{mL})$ were added to $20 \mathrm{~mL}$ tubes containing $5 \mathrm{~mL}$ of anthrone reagent. After mixing well, the solution was incubated at $100^{\circ} \mathrm{C}$ in a constant-temperature water bath for 12 to $13 \mathrm{~min}$, after which it was cooled down to room temperature immediately after color development to measure the absorbance at $630 \mathrm{~nm}$ using a spectrophotometer. All samples were then diluted as appropriate for subsequent measurements. The rate of starch digestion was converted to starch contents, calculated from the D-glucose contents of samples.

\section{Statistics}

Data of serum MEL, GIH, duodenum $\alpha$-amylase, D-glucose, ruminal characteristics, apparent rates of crude protein disappearance, and apparent rates of starch disappearance were analyzed using Student's paired t-test. All statistical analyses were performed using SPSS software package (SPSS, Chicago,

Table 1. Ruminal characteristics in Korean native steers fed basal diet and rumen-protected L-tryptophan (RPL-T)

\begin{tabular}{|c|c|c|c|c|}
\hline \multirow{2}{*}{ Items } & \multicolumn{2}{|c|}{ Treatment $^{1)}$} & \multirow{2}{*}{ SEM } & \multirow{2}{*}{$p$-value ${ }^{2)}$} \\
\hline & Control & RPL-T & & \\
\hline pH & 6.34 & 6.28 & 0.09 & ns \\
\hline Total VFA, mmol & 82.80 & 77.40 & 6.84 & ns \\
\hline \multicolumn{5}{|c|}{ VFA concentration, mol/100 mL } \\
\hline Acetate, mol (\%) & 58.00 & 55.40 & 1.06 & ns \\
\hline Propionate, mol (\%) & 20.90 & 23.10 & 0.74 & ns \\
\hline Butyrate, mol (\%) & 14.70 & 15.40 & 0.42 & ns \\
\hline Isobutyrate, mol (\%) & 1.38 & 1.23 & 0.12 & ns \\
\hline Valerate, mol (\%) & 1.74 & 1.87 & 0.07 & ns \\
\hline Isovalerate, mol (\%) & 3.26 & 3.04 & 0.28 & ns \\
\hline Acetate:propionate & 2.85 & 2.57 & 0.13 & ns \\
\hline $\mathrm{NH}_{3}-\mathrm{N}, \mathrm{mg} / \mathrm{L}$ & 123.00 & 117.60 & 16.54 & ns \\
\hline
\end{tabular}

RPL-T, rumen-protected L-tryptophan; SEM, standard error of the mean; VFA, volatile fatty acids; BW, body weight.

1) Control, concentrate $7 \mathrm{~kg} / \mathrm{d}+$ rice straw $1 \mathrm{~kg} / \mathrm{d}+$ excipient average $110.8 \mathrm{mg} /$ $\mathrm{kg} \mathrm{BW}$; RPL-T, concentrate $7 \mathrm{~kg} / \mathrm{d}$ +rice straw $1 \mathrm{~kg} / \mathrm{d}+$ RPL-T $191.1 \mathrm{mg} / \mathrm{kg}$ BW.

${ }^{2)} \mathrm{p}$-values were calculated by paired t-test ( $\mathrm{ns}=$ non-significant).
IL, USA). Statistical significance was considered when the pvalue was less than 0.05 or 0.01 .

\section{RESULTS}

No significant differences ( $\mathrm{p}>0.05)$ were observed in ruminal $\mathrm{pH}, \mathrm{NH}_{3}-\mathrm{N}$, and total VFA including the levels of acetate, propionate, butyrate, isobutyrate, valerate, isovalerate, and the acetate-to-propionate ratio between two groups (Table 1). The rates of CP flow and digestion in each section of the intestine according to the dietary supply of RPL-T are summarized in Table 2. Crude protein uptake by the RPL-T group was $8.6 \mathrm{~g} / \mathrm{d}$ higher $(\mathrm{p}<0.0001)$ than that by the control group. However, no significant differences $(\mathrm{p}>0.05)$ were found in the flow of $\mathrm{CPs}$ or in the amount of digesta flowing into the small intestine between the RPL-T group and the control.

The flow rate and digestion rate of starch in each section of the intestine according to the dietary supply of RPL-T are summarized in Table 3. Starch content in the feces of the RPL-T group was significantly lower $(\mathrm{p}<0.05)$ than that in the control group, although the influx of starch to the small intestine was significantly higher $(\mathrm{p}<0.05)$ than that in the control group. Both the rate and amount of starch digestion increased $(\mathrm{p}<0.05)$ in total tract following by RPL-T administration.

The effects of oral RPL-T administration on serum MEL synthesis, intestinal hormones (secretin and CCK), and $\alpha$-amylase activity of pancreatic exocrine duodenal fluids are shown in Figure 1 and Table 4. Serum MEL level increased $(p<0.05)$ following oral administration of RPL-T compared to that in the control group, however, there was no significant

Table 2. Apparent crude protein loss in each segment of the gastrointestinal tract in Korean native steers fed basal diet and RPL-T

\begin{tabular}{|c|c|c|c|c|}
\hline \multirow{2}{*}{ Items } & \multicolumn{2}{|c|}{ Treatment $^{1)}$} & \multirow{2}{*}{ SEM } & \multirow{2}{*}{ p-value ${ }^{2)}$} \\
\hline & Control & RPL-T & & \\
\hline Crude protein intake $(\mathrm{g} / \mathrm{d})$ & $972.4^{b}$ & $981.0^{\mathrm{a}}$ & 1.62 & $<0.0001$ \\
\hline Duodenal flow (g/d) & 480.9 & 477.3 & 6.15 & ns \\
\hline Fecal flow (g/d) & 193.4 & 184.4 & 4.86 & ns \\
\hline \multicolumn{5}{|l|}{ Disappearance (g/d) } \\
\hline Rumen & 491.5 & 503.7 & 6.52 & ns \\
\hline Intestine & 287.5 & 292.9 & 7.01 & ns \\
\hline Total tract & 779.0 & 796.6 & 5.68 & ns \\
\hline \multicolumn{5}{|l|}{ Disappearance (\%) } \\
\hline Rumen, of intake & 50.5 & 51.3 & 0.64 & ns \\
\hline Intestine, of flow & 59.8 & 61.3 & 1.05 & ns \\
\hline Total tract, of intake & 80.1 & 81.2 & 0.51 & ns \\
\hline
\end{tabular}

RPL-T, rumen-protected L-tryptophan; SEM, standard error of the mean; BW, body weight.

1) Control, concentrate $7 \mathrm{~kg} / \mathrm{d}$ + rice straw $1 \mathrm{~kg} / \mathrm{d}$ + excipient average $110.8 \mathrm{mg} / \mathrm{kg}$ BW; RPL-T, concentrate $7 \mathrm{~kg} / \mathrm{d}$ + rice straw $1 \mathrm{~kg} / \mathrm{d}+\mathrm{RPL}-\mathrm{T} 191.1 \mathrm{mg} / \mathrm{kg}$ BW.

${ }^{2)} p$-values were calculated by paired $t$-test ( ${ }^{*} p<0.05$ and $n s=$ non-significant).

$a, b$ Values within a row with different superscripts differ significantly at $p<0.05$. 
Table 3. Apparent starch loss in each segment of the gastrointestinal tract in Korean native steers fed basal diet and RPL-T

\begin{tabular}{|c|c|c|c|c|}
\hline \multirow{2}{*}{ Items } & \multicolumn{2}{|c|}{ Treatment $^{1)}$} & \multirow{2}{*}{ SEM } & \multirow{2}{*}{$p$-value ${ }^{2}$} \\
\hline & Control & RPL-T & & \\
\hline Starch intake (g/d) & $3,196.0$ & $3,196.0$ & 0.00 & \\
\hline Duodenal flow (g/d) & 797.7 & 882.3 & 117.90 & ns \\
\hline Fecal flow (g/d) & $224.4^{a}$ & $164.2^{b}$ & 15.72 & * \\
\hline \multicolumn{5}{|l|}{ Disappearance (g/d) } \\
\hline Rumen & $2,398.7$ & $2,314.1$ & 117.90 & ns \\
\hline Intestine & 573.3 & 718.1 & 119.88 & ns \\
\hline Total tract & $2,972.0^{b}$ & $3,032.2^{\mathrm{a}}$ & 15.72 & * \\
\hline \multicolumn{5}{|l|}{ Disappearance (\%) } \\
\hline Rumen, of intake & 75.0 & 72.4 & 3.69 & ns \\
\hline Intestine, of flow & 67.8 & 78.9 & 4.39 & ns \\
\hline Total tract, of intake & $93.0^{b}$ & $94.9^{\mathrm{a}}$ & 0.49 & * \\
\hline
\end{tabular}

RPL-T, rumen-protected L-tryptophan; SEM, standard error of the mean; BW, body weight.

1) Control, concentrate $7 \mathrm{~kg} / \mathrm{d}$ + rice straw $1 \mathrm{~kg} / \mathrm{d}$ + excipient average $110.8 \mathrm{mg} / \mathrm{kg}$ BW; RPL-T, concentrate $7 \mathrm{~kg} / \mathrm{d}$ + rice straw $1 \mathrm{~kg} / \mathrm{d}+$ RPL-T $191.1 \mathrm{mg} / \mathrm{kg} \mathrm{BW}$.

${ }^{2)} \mathrm{p}$-values were calculated by paired t-test.

a,b Values within a row with different superscripts differ significantly at $p<0.05$.

(A)

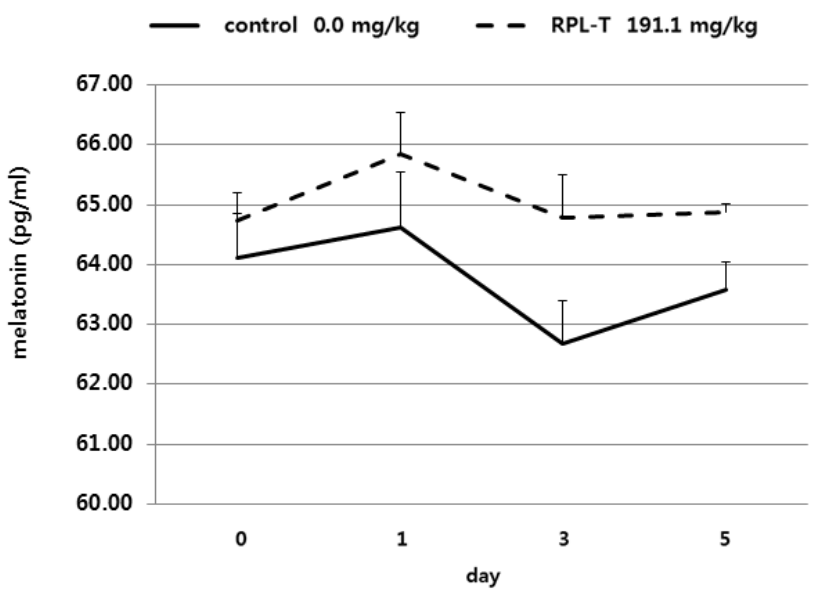

(C)

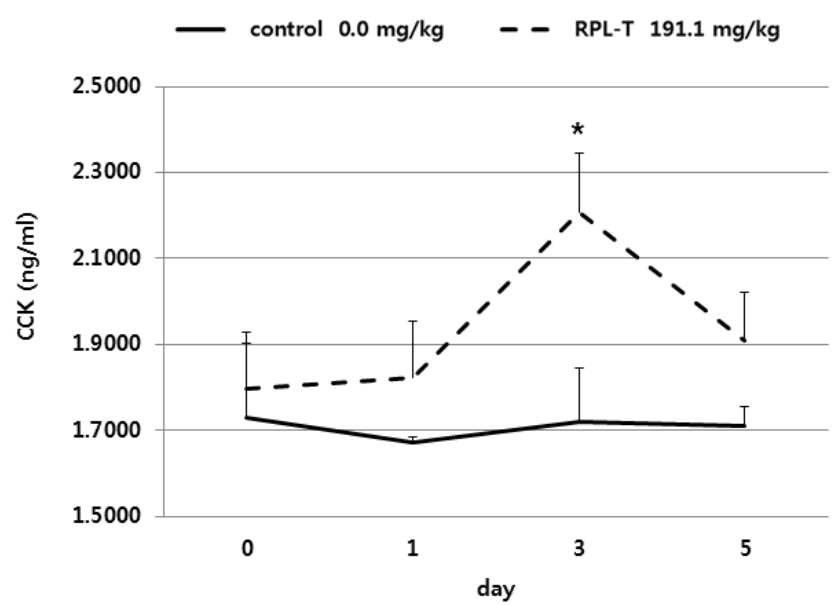

difference ( $\mathrm{p}>0.05)$ among all periods (i.e., day $0,1,3$, and 5). An increase $(\mathrm{p}<0.05)$ in MEL was observed in the RPL-T group compared to that in the control group (Table 4). There was no difference ( $p>0.05)$ in CCK concentration in the RPLT group until day 1 , with a rapid and significant increase $(\mathrm{p}<$ 0.05 ) at day 3 compared to the control group (Figure 1). Similarly, there was no significant increase in $\alpha$-amylase activity in the duodenum digesta of the RPL-T group until day 1 . However, it was significantly increased $(\mathrm{p}<0.05)$ at day 3 and 5 compared to that in the control.

Changes in the D-glucose content in feces followed by oral administration of RPL-T are shown in Figure 2. The D-glucose contents in the feces of the group orally administered RPL-T were significantly decreased $(\mathrm{p}<0.05)$ at day 5 compared to those in the control group. However, no change $(p>0.05)$ was found at day 0,1 , or 3 compared to the control. The rate of starch digestion was also significantly increased $(p<0.05)$ in the oral RPL-T group compared to the control group (Table 4).

(B)

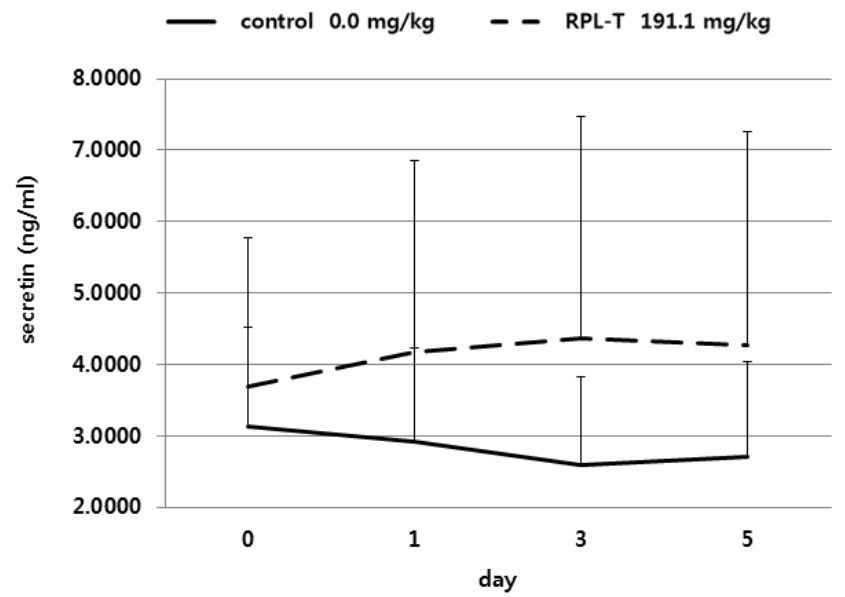

(D)

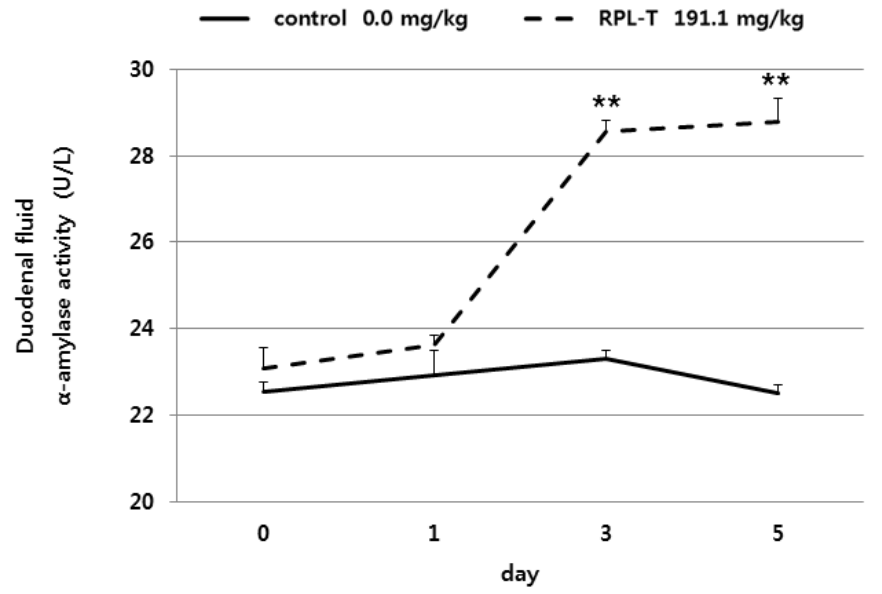

Figure 1. Changes in the levels of serum melatonin (A), secretin (B), CCK (C), and duodenum a-amylase (D) in Korean native steers fed RPL-T. CCK, cholecystokinin; RPL-T, rumen-protected L-tryptophan. Mean \pm standard error, ${ }^{*} \mathrm{p}<0.05,{ }^{* *} \mathrm{p}<0.01$ (Student's paired $t$-test, control vs RPL-T at $191.1 \mathrm{mg} / \mathrm{kg}$ body weight). - Control group, - RPL-T group. 
Table 4. Effect of oral administration of rumen-protected L-tryptophan for 5 days on levels of serum MEL, GIH, and duodenum a-amylase in Korean native steers

\begin{tabular}{lcc}
\hline Items & Control & RPL-T \\
\hline Hormones & & \\
$\quad$ Melatonin $(\mathrm{pg} / \mathrm{mL})$ & $63.75 \pm 0.413$ & $65.06 \pm 0.263^{*}$ \\
$\quad$ Cholecystokinin $(\mathrm{ng} / \mathrm{mL})$ & $1.71 \pm 0.054$ & $1.93 \pm 0.069^{*}$ \\
$\quad$ Secretin $(\mathrm{ng} / \mathrm{mL})$ & $2.90 \pm 0.726$ & $4.13 \pm 1.368$ \\
Enzyme & & \\
$\quad$ a-Amylase activity (U/L) & $22.81 \pm 0.174$ & $26.01 \pm 0.712^{* *}$ \\
\hline
\end{tabular}

MEL, melatonin; GIH, gastrointestinal hormones; RPL-T, rumen-protected L-tryptophan; BW, body weight.

${ }^{*} p<0.05,{ }^{* *} p<0.01$ (Student's paired t-test, control vs RPL-T $191.1 \mathrm{mg} / \mathrm{kg} \mathrm{BW).}$

\section{DISCUSSION}

The reason why we measured ruminal fluid characteristics in the animals including $\mathrm{pH}, \mathrm{NH}_{3}-\mathrm{N}$, and VFAs was to find out if the encapsulated $\mathrm{L}-\mathrm{T}$ could be successfully bypassed via rumen. Although bypassing $100 \%$ of encapsulated L-T is not assumed. However, as shown in Table 1, there was no difference in ruminal fermentation based on the dietary supply of RPL-T between two groups, including for ruminal $\mathrm{pH}$, total VFA, ruminal ammonia concentration, and other factors. This phenomenon may be due to feeding the encapsulating L-T that helped to bypass L-T through rumen. In other words, the rate of retained L-T in the rumen was not high enough to affect rumen fluid characteristics. In addition, Ludden et al [23] reported that an increase in the protein supply to ruminants could lead to an increase in branched-chain VFAs. However, dietary supply of RPL-T showed no effect on rumen fermentation in the present study. A previous study reported that $\mathrm{L}-\mathrm{T}$ could be degraded by microorganisms in the rumen be-

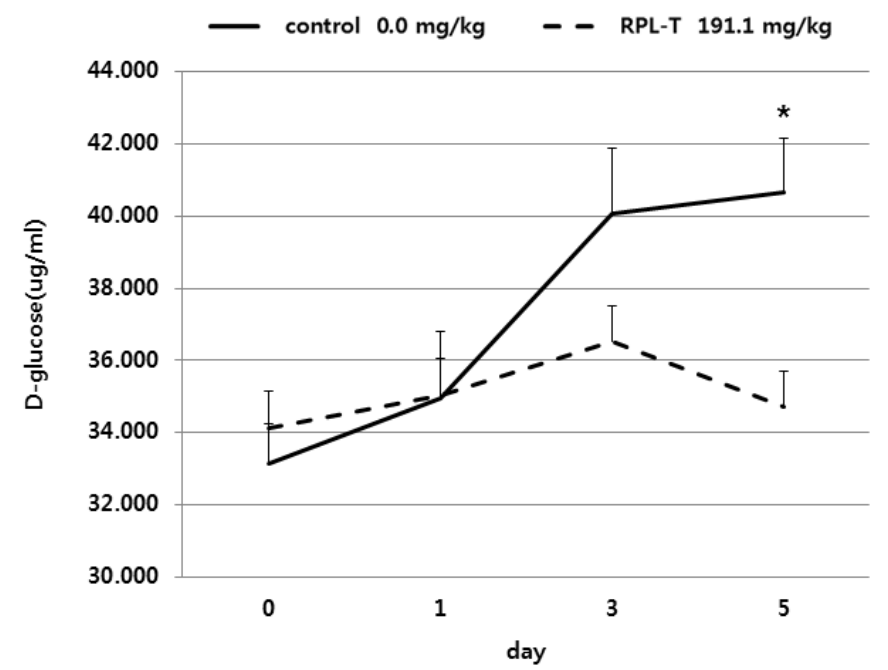

fore entering the small intestine for absorption in ruminants [5]. However, this is unlikely during ruminal fermentation because L-T was protected by fats and carbohydrates in RPL-T product in order to prevent degradation by microorganisms in the rumen. As we fed rumen protected L-T, no changes in ruminal fermentation could be expected. The reason why we measured ruminal fermentation characteristics was that we wanted to make sure the product remains intact in the rumen. Conforming with our expectation, rumen fluid characteristics showed no alteration following oral administration of RPL-T indicating successful bypassing of the product through the rumen and that it escaped degradation.

Table 2 shows the flow and digestion rate of $\mathrm{CP}$ at each section of the intestine according to the dietary supply of RPLT. Although the uptake of CP was higher in the RPL-T group, RPL-T had no effect on the contents or the digestion rate of $\mathrm{CP}$ in each section of the intestine. Titgemeyer et al [24] noted that the dietary supply of ruminally undegradable proteins could increase the influx of $\mathrm{N}$ and amino acids into the small intestines. In addition, Goedeken et al [25] reported increased influx of $\mathrm{N}$ and amino acids into the small intestine, including increased nitrogen availability and growth. However, an excessive supply of rumen-undegradable protein (RUP) could decrease the efficiency of amino acid flow into the small intestine and protein synthesis [26]. High levels of RUP can limit the protein synthesis of microorganisms, leading to decreased concentrations of the final products of ruminal degradation, such as $\mathrm{NH}_{3}-\mathrm{N}$, amino acids, or branched chain VFAs [27]. However, the amount of RUP in the present study was not excessive because the influx of RPL-T into the small intestine was decreased. RPL-T had no effect on the environment of the rumen or on ruminal microorganisms. It only affected the protein being absorbed or used in the small intestine due to

Figure 2. Effects of oral RPL-T on D-glucose content in feces of Korean native steers. RPL-T, rumen-protected L-tryptophan. Mean \pm standard error, * $p<0.05$ (Student's paired $t$-test, control vs RPL-T at $191.1 \mathrm{mg} / \mathrm{kg}$ body weight). - Control group, - - - RPL-T group. 
the fact that it was encapsulated to be protected in the rumen.

The D-glucose contents in feces decreased over the time following by oral administration of RPL-T (Figure 2), with a significant decrease on day 5 compared to the control group. These results may be due to the direct stimulation of I-cells in the mucosa by RPL-T entering to the duodenum, and through the indirect stimulation of endogenous MEL synthesized from L-T [14]. Both I-cells and endogenous MEL may have induced the secretion of intestinal CCK, which eventually enhanced the activity of pancreatic $\alpha$-amylase and decreased fecal Dglucose contents [14]. When considering the flow and digestion rate of starch at each section of the intestine according to the dietary supply of RPL-T (Table 3), a significant decrease in starch contents was observed in the RPL-T group compared to the control group as shown in the present study. Small intestinal starch assimilation is limited in ruminants [28]. Richards et al [28] showed that comparing with infusing starch alone, infusing protein with starch into the small intestine enhanced small intestinal starch disappearance. They also reported that the products of feed protein breakdown, such as peptides or amino acids, entering to the small intestine could modulate starch bioavailability in the small intestine and RUP, thus enhancing their bioavailability [28]. In particular, Choi et al [29] noted that an additional dietary supply of soluble proteins can lead to an influx of amino acids and peptides into the lower intestines, thus affecting the practical productivity of ruminants such as growth, milk production, and other factors. Therefore, oral administration of RPL-T affected MEL concentration and CCK secretion (Table 4) associated with starch digestion by enhancing the absorption of CPs $(\mathrm{L}-\mathrm{T})$ in the rumen and small intestine and eventually enhancing the rate of starch digestion in the small intestine.

A significant increase in serum MEL, CCK concentration, and pancreatic $\alpha$-amylase activity in the duodenum were observed in the RPL-T group compared to the control group (Figure 1; Table 4). This is consistent with the findings of Barry et al [30], who reported that increased absorption of amino acids can modulate the hormonal status. Oral administration of L-T could reportedly increase plasma concentration of MEL in humans [1], chickens, mice [6], and cows [31]. In this study, and in agreement with the above studies, the aforementioned results in human and the other animal species were confirmed. Furthermore, induction of endogenous MEL by L-T strongly stimulated the secretion of pancreatic proteins [14]. Leja-Szpak et al [14] reported that administration of the essential amino acid L-T to mice can affect the synthesis of the pineal hormone MEL. Therefore, since both L-T and MEL are closely related to the intestinal hormone CCK [4], the production of pancreatic $a$-amylase was increased. In general, the secretion of CCK is stimulated by the degradation of chain peptides and small molecules that enter the duodenum [32]. Secretion of CCK is related to the uptake of chained amino acids [33].
Additionally, in our study, there was no significant difference in the daily CCK between the L-T and control group until day 1 . CCK concentrations increased significantly at day 3 in the L-T group but decreased at day 5 . This could be related to the amount of endogenous MEL synthesized from L-T [1]. The synthesis of MEL may not be continuously maintained at high level. Similarly, oral RPL-T had no significant effect on the daily CCK concentration compared to the control group until day 1 . However, CCK activity increased significantly at day 3 and 5 . Protein hydrolysates can flow into the small intestine and instantly stimulate the secretion of CCK by isolated mucosal cells [34] or STC-1 cells of neurosecretion [35]. Secreted CCK can stimulate acinar cells in the pancreas by the afferent pathway of the pneumogastric nerves to stimulate the secretion of pancreatic fluids [36]. However, more studies are needed to determine how CCK stimulates CCK receptors of acinar cells in the pancreas and to confirm this result.

Serum secretin in the oral RPL-T group was higher than that in the control group. However, variability among individual responses made it difficult to draw a conclusion in this regard. Secretin has been extensively investigated for its peripheral effects on digestion [37]. Postprandial secretion of pancreatic fluids largely depends on the activation of cholinergic postganglionic neurons of the pancreas by valgus reflex of intestinal hormones, such as secretin and CCK [38]. Rausch et al [39] reported an increase in the synthesis of pancreatic proteins by a maximum of $90 \%$ compared to the control group when secretin was infused for 6 and $12 \mathrm{~h}$ into the acinar cells in mice. The aforementioned results complied with the recent rat study [38]. Manso et al [40] also showed that the total amount of protein synthesized from the pancreas and amylase secretion increased when secretin administered to mice with acute pancreatitis. However, little is known about the relationship between L-T and the secretion of secretin. The relationship between oral administration of RPL-T and the secretion of secretin remained unclear in the present study and thus need further investigations.

\section{CONCLUSION}

Taken together, oral administration of RPL-T at the rate of $191.1 \mathrm{mg} / \mathrm{kg}$ BW is advisable due to its effects on consistently increasing CCK concentration, pancreatic $\alpha$-amylase activity in duodenal fluids, and starch digestion rate in the small intestine.

\section{CONFLICT OF INTEREST}

We certify that there is no conflict of interest with any financial organization regarding the material discussed in the manuscript. Lee K-W is an employee of Life Science Technology, Inc.. 


\section{ACKNOWLEDGMENTS}

This work was supported by the Korea Institute of Planning and Evaluation for Technology in Food, Agriculture, Forestry (IPET) through the Agri-Bio Industry Technology Development Program (117030-3).

\section{REFERENCES}

1. Hsia LC, Hsu JH, Liao CT. The Effect of varying levels of tryptophan on growth performance and carcass characteristics of growing and finishing broilers. Asian-Australas J Anim Sci 2005;18:230-4. https://doi.org/10.5713/ajas.2005.230

2. Tabiri HY, Sato K, Takahashi K, Toyomizo M, Akiba Y. Effects of heat stress and dietary tryptophan on performance and plasma amino acid concentrations of broiler chickens. AsianAustralas J Anim Sci 2002;15:247-53. https://doi.org/10.5713/ ajas.2002.247

3. Feng P, Zhao W, XIe Q, Zeng T, Lu L, Yang L. Polymorphisms of melatonin receptor genes and their associations with egg production traits in Shaoxing duck. Asian-Australas J Anim Sci 2018;31:1535-41. https://doi.org/10.5713/ajas.17.0828

4. Ya K, Fang J, Yin YL, Feng ZM, Tang ZR, Wu G. Tryptophan metabolism in animals: important roles in nutrition and health. Front Biosci 2011;3:286-97. https://doi.org/10.2741/s152

5. Ma H, Cheng J, Zhu X, Jia Z. Effects of rumen-protected tryptophan on performance, nutrient utilization and plasma tryptophan in cashmere goats. Afric J Biotechnol 2011;10: 5806-11. https://doi.org/10.5897/AJB10.393

6. Lee SB, Choi CW, Jin YC, et al. Effect of oral administration of intact casein on gastrointestinal hormone secretion and pancreatic alpha-amylase activity in Korean native steer. AsianAustralas J Anim Sci 2013;26:654-60. https://doi.org/10.5713/ ajas.2012.12510

7. Lepage O, Larson ET, Mayer I, Winberg S. Tryptophan affects both gastrointestinal melatonin production and interrenal activity in stressed and nonstressed rainbow trout. J Pineal Res 2005;38:264-71. https://doi.org/10.1111/j.1600-079X.2004. 00201.x

8. Charney DS, Heninger GR, Reinhard Jr. JF, Strenberg DE, Hafstead KM. The effect of intravenous L-tryptophan on prolactin and growth hormone and mood in healthy subjects. Psychopharmacology 1982;77:217-22. https://doi.org/10.1007/ BF00464569

9. Zinn RA. Comparative feeding value of steam-flaked corn and sorghum in finishing diets supplemented with or without sodium bicarbonate. J Anim Sci 1991;69:905-16. https://doi. org/10.2527/1991.693905x

10. Harmon DL, Taylor CC. Factors influencing assimilation of dietary starch in beef and dairy cattle. In: Proceedings of the Southwest Nutrition Conference, Phoenix, AZ, USA: University of Arizona; 2005. pp. 55-66.
11. Bello AU, Idrus Z, Men GY, Award EA, Soleimani Farjam A. Gut microbiota and transportation stress response affected by tryptophan supplementation in broiler chickens. Ital J Anim Sci 2018;17:107-13. https://doi.org/10.1080/182805 1X.2017.1340814

12.Liang H, Dai Z, Liu N, et al. Dietary L-tryptophan modulates the structural and functional composition of the intestinal microbiome in weaned piglets. Front Microbiol 2018;9:1736. https://doi.org/10.3389/fmicb.2018.01736

13.Lee SB, Lee KW, Wang T, et al. Intravenous administration of L-tryptophan stimulates gastrointestinal hormones and melatonin secretions: study on beef cattle. J Anim Sci Technol 2019;61:239-44. https://doi.org/10.5187/jast.2019.61.4.239

14.Leja-Szpak A, Jaworek J, Nawrot-Porabka K, et al. Modulation of pancreatic enzyme secretion by melatonin and its precursor; L-tryptophan. Role of CCK and afferent nerves. J Physiol Pharmacol 2004;55 (Suppl 2):33-46.

15.Lee $\mathrm{KH}$, Wang T, Jin YC, et al. Identification of proteins involved in the pancreatic exocrine by exogenous ghrelin administration in Sprague-Dawley rats. J Anim Sci Technol 2014;56:6. https://doi.org/10.1186/2055-0391-56-6

16. National Institute of Animal Science (NIAS). Korean Feeding Standard for Hanwoo. Suwon, Korea: RDA; 2007.

17. Santos KA, Stern MD, Satter LD. Protein degradation in the rumen and amino acid absorption in the small intestine of lactating dairy cattle fed various protein sources. J Anim Sci 1984;58:244-55. https://doi.org/10.2527/jas1984.581244x

18. AOAC (Association of Official Analytical Chemists) International. Official Methods of Analysis of the Association of Official Analytical Chemists International, 15th edn. Washington, DC, USA: AOAC International; 1990.

19. Chaney AL, Marbach EP. Modified reagents for determination of urea and ammonia. Clin Chemist 1962;8:130-2.

20.Erwin ES, Marco GJ, Emery EM. Volatile fatty acid analyses of blood and rumen fluid by gas chromatography. J Dairy Sci 1961;44:1768-71. https://doi.org/10.3168/jds.S0022-0302(61) 89956-6

21. Roe JH. The determination of sugar in blood and spinal fluid with anthrone reagent. J Biol Chemist 1955;212:335-43.

22. McCready RM, Guggolz J, Silviera V, Owens HS. Determination of starch and amylose in vegetable. Analytic Chemist 1950;22:1156-8. https://doi.org/10.1021/ac60045a016

23.Ludden PA, Wechter TL, Hess BW. Effects of oscillating dietary protein on ruminal fermentation and site and extent of nutrient digestion in sheep. J Anim Sci 2002;80:3336-46. https://doi. org/10.2527/2002.80123336x

24. Titgemeyer EC, Merchen NR, Berger LL. Evaluation of soybean meal, corn gluten meal, blood meal and fish meal as sources of nitrogen and amino acids disappearing from the small intestine of steers. J Anim Sci 1989;67:262-75. https://doi. org/10.2527/jas1989.671262x

25. Goedeken FK, Klopfenstein TJ, Stock RA, Britton RA, Sindt 
MH. Protein value of feather meal for ruminants as affected by blood additions. J Anim Sci 1990;68:2936-44. https://doi. org/10.2527/1990.6892936x

26.Siddons RC, Paradine J, Gale DL, Evans RT. Estimation of the degradability of dietary protein in the sheep rumen by in vivo and in vitro procedures. Br J Nutr 1985;54:545-61. https://doi.org/10.1079/BJN19850139

27. Cecava MJ, Parker JE. Intestinal supply of amino acids in steers fed ruminally degradable and undegradable crude protein sources alone and in combination. J Anim Sci 1993;71:1596605. https://doi.org/10.2527/1993.7161596x

28. Richards CJ, Swanson KC, Paton SJ, Harmon DL, Huntington GB. Pancreatic exocrine secretion in steers infused postruminally with casein and cornstarch. J Anim Sci 2003;81:10516. https://doi.org/10.2527/2003.8141051x

29. Choi CW, Vanhatalo A, Ahvenjärvi S, Huhtanen P. Effects of several protein supplements on flow of soluble non-ammonia nitrogen from the forestomach and milk production in dairy cows. Anim Feed Sci Technol 2002;102:15-33. https:/doi.org/ 10.1016/S0377-8401(02)00251-1

30. Barry TN, Manley TR, Davis SR, Redekopp C. Protein metabolism and response to abomasal infusion of casein plus methionine in growing lambs fed fresh primary growth ryegrass/ clover pasture ad libitum. In: Thomson DJ, Beever DE, Gunn RG, editors. The British Society of Animal Production. Leeds, UK: University of Leeds, 1982;46-148.

31. Kollmann MT, Locher M, Hirche F, Eder K, Meyer HH, Bruckmaier RM. Effects of tryptophan supplementation on plasma tryptophan and related hormone levels in heifers and dairy cows. Domest Anim Endocrinol 2008;34:14-24. https://doi. org/10.1016/j.domaniend.2006.09.005

32. Go VL, Hofmann AF, Summerskill WH. Pancreozymin bioassay in man based on pancreatic enzyme secretion: potency of specific amino acids and other digestive products. J Clin Invest 1970;49:1558-64. https://doi.org/10.1172/JCI106373
33. Hashimoto N, Hara H. Dietary branched-chain amino acids suppress the expression of pancreatic amylase mRNA in rats. Biosci Biotechnol Biochem 2004;68:1067-72. https://doi.org/ 10.1271/bbb.68.1067

34. Nishi T, Hara H, Kasai T. Guanidinated casein hydrolysate stimulates pancreatic secretagogue release by direct action to the intestine in rats. Proc Soc Exp Biol Med 1998;218:35764. https://doi.org/10.3181/00379727-218-44304

35. Cordier-Bussat M, Bernard C, Haouche S, et al. Peptones stimulate cholecystokinin secretion and gene transcription in the intestinal cell line STC-1. Endocrinol 1997;138:1137-44. https://doi.org/10.1210/endo.138.3.5023

36.Li Y, Owyang C. Vagal afferent pathway mediates physiological action of cholecystokinin on pancreatic enzyme secretion. J Clin Invest 1993;92:418-24. https://doi.org/10.1172/JCI 116583

37.Pang YY, Chen XY, Xue Y, Han HX, Chen L. Effects of secretin on neuronal activity and feeding behavior in central amygdala of rats. Peptides 2015;66:1-8. https://doi.org/10.1016/j.pepti des.2015.01.012

38. Chung SA, Rotstein O, Greenberg GR, Diamant NE. Mechanisms coordinating gastric and small intestinal MMC: role of extrinsic innervation rather than motilin. Ame J Physiol 1994;267:G800-9. https://doi.org/10.1152/ajpgi.1994.267.5. G800

39. Rausch U, Vasiloudes P, Rudiger K, Kern HF. In-vivo stimulation of rat pancreatic acinar cells by infusion of secretin. I. Changes in enzyme content, pancreatic fine structure and total rate of protein synthesis. Cell Tissue Res 1985;242:6339. https://doi.org/10.1007/BF00225430

40. Manso MA, De Dios I, San Roman JI, Calvo JJ, Lopez MA. Effect of secretin on pancreatic juice proteins in caeruleininduced acute pancreatitis in the rat. Peptides 1989;10:25560. https://doi.org/10.1016/0196-9781(89)90027-2 